\title{
Trends in Soil Microbial Inoculants Research: A Science Mapping Approach to Unravel Strengths and Weaknesses of Their Application
}

\author{
Loredana Canfora $^{1}\left(\mathbb{D}\right.$, Corrado Costa $^{2} \oplus$, Federico Pallottino ${ }^{2}\left(\mathbb{D}\right.$ and Stefano Mocali ${ }^{3, *}$ \\ 1 Council for Agricultural Research and Analysis of the Agricultural Economy, Research Centre for Agriculture \\ and Environment, 00182 Roma, Italy; loredana.canfora@crea.gov.it \\ 2 Council for Agricultural Research and Analysis of the Agricultural Economy, Research Centre for \\ Engineering and Agro-Food Processing, 00015 Monterotondo, Italy; corrado.costa@crea.gov.it (C.C.); \\ federico.pallottino@crea.gov.it (F.P.) \\ 3 Council for Agricultural Research and Analysis of the Agricultural Economy, Research Centre for Agriculture \\ and Environment, 50125 Cascine del Riccio, Italy \\ * Correspondence: stefano.mocali@crea.gov.it
}

Citation: Canfora, L.; Costa, C.; Pallottino, F.; Mocali, S. Trends in Soil Microbial Inoculants Research: A Science Mapping Approach to Unravel Strengths and Weaknesses of Their Application. Agriculture 2021, 11, 158. https://doi.org/10.3390/ agriculture11020158

Academic Editor: Riccardo Scotti

Received: 13 December 2020

Accepted: 9 February 2021

Published: 16 February 2021

Publisher's Note: MDPI stays neutral with regard to jurisdictional claims in published maps and institutional affiliations.

Copyright: (c) 2021 by the authors. Licensee MDPI, Basel, Switzerland. This article is an open access article distributed under the terms and conditions of the Creative Commons Attribution (CC BY) license (https:// creativecommons.org/licenses/by/ $4.0 /)$
Abstract: Microbial inoculants are widely accepted as potential alternatives or complements to chemical fertilizers and pesticides in agriculture. However, there remains a lack of knowledge regarding their application and effects under field conditions. Thus, a quantitative description of the scientific literature related to soil microbial inoculants was conducted, adopting a science mapping approach to observe trends, strengths, and weaknesses of their application during the period of 2000-2020 and providing useful insights for future research. Overall, the study retrieved 682 publications with an increasing number during the 2015-2020 period, confirming China, India, and the U.S. as leading countries in microbial inoculants research. Over the last decade, the research field emphasized the use of microbial consortia rather than single strains, with increasing attention paid to sustainability and environmental purposes by means of multidisciplinary approaches. Among the emerging topics, terms such as "persistence" indicate the actual need for detecting and monitoring the persistence and fate of soil microbial inoculants. On the other hand, the low occurrence of terms related to failed studies as well as formulation processes may have limited the overall comprehension of the real potential of microbial inoculants to date. In conclusion, successful application of soil microbial inoculants in agriculture requires filling the fundamental knowledge gaps related to the processes that govern dynamics and interactions of the inoculants with soil and its native microbiota.

Keywords: soil; microorganisms; microbial inoculants; bio-inocula; biofertilizer; microbial inoculant detection; science mapping approach; bibliography

\section{Introduction}

The application of microbial inoculants in agriculture has become a cutting-edge research topic in recent years, since the use of microorganisms, particularly plant-growthpromoting microorganisms (PGPMs), represents good support for crop production and protection from pests and pathogens and offers a means to reduce the use of chemical fertilizer and pesticides [1-7]. Although the application of microbial inoculants has been carried out since ancient times [8-10], during the last three decades several microbial inoculants have received increasing attention regarding their commercial potential [11-13]. Microbial inoculants are marketed as alternative or integrative products to conventional fertilizers and pesticides, thus expanding the farmers' "friendly management toolbox" and making their application extremely attractive. Most of the studies conducted on microbial inoculants over the last decade have revealed significant benefits regarding biotic and abiotic stresses [14-28]. An enormous variety of microorganisms belonging to several taxa of fungi and bacteria closely associated with plants and rhizospheric soil can be 
utilized for the formulation of bioproducts for plant growth and protection. It can be noted that several terms, such as "bio-inocula" or "bioinoculant", have been commonly used to refer to biofertilizers or microbial-based products [29-32]. However, despite the considerable number of studies and evidence of beneficial microorganisms (PGPMs, plant growth-promoting bacteria (PGPB), biocontrol agents, and biostimulants), the application of microbial-based products or "microbial inoculants" is still limited and hindered by several factors [33,34]. In fact, while the vast literature clearly shows their beneficial "traits", several issues, such as the potential environmental impact, the fate and the tracking of the inocula into a new environment [35], and limited knowledge of the interrelationships occurring between microorganisms and plants, are still considerable barriers for a concrete adoption. Moreover, the limited understanding of the ecological traits of most soil microbes is emerging due to the gap between the successful in vitro applications of bioinocula and their success in field conditions [36-38]. In this scenario, the present works applied a science mapping approach as a "hand lens" to observe trends, strengths, and weaknesses of their application and to measure the related scientific production. The science mapping approach allows for a spatial representation of how disciplines, documents, countries, and authors are integrated. This approach has been successfully applied to several research fields to date [39-46]. To the best of our knowledge, the science mapping approach has never been applied to analyze soil microbial inoculant application.

The present paper reports a science mapping analysis of published soil microbial inoculants research data for the time frame of 2000-2020. The records before 2000 were too few in number (less than 100) and fragmented. The current work aims to (i) demonstrate the spatial-temporal evolution of soil microbial inoculant research; (ii) determine the strengths and the weaknesses of their application, which may serve as a potential guide for future research as well as to predict emerging topics. Overall, the work provides useful representations for scientific communities engaged in broad and complex microbial-based products research and policymakers involved in the development of the regulatory process of these products. The keywords used for the Scopus search were "soil, microorganisms, microbial inoculants, consortia, bio-inocula, biofertilizer, microbial-based products, bio-effectors, detection, monitoring, tracking and traceability". The present exploratory survey opens opportunities for further thematic, disciplinary, methodological, spatial, and temporal analysis. Furthermore, it makes a case for consolidated evidence, collaborative writing, and multidisciplinary research through a "team science" approach [47,48].

\section{Materials and Methods}

\subsection{Database Search}

The Scopus database was consulted on 8 May 2020 and used to retrieve bibliographic records related to the application and detection of soil microbial inoculants for the period of 2000-2020. The following keywords were used to identify relevant publications in the combined fields of title, abstract, and keywords (per publication): Soil AND (microorganism OR microorganisms) AND (microbial AND inoculants OR consortia OR bio-inocula OR biofertilizer OR bioinoculant OR microbial-based OR bioproducts OR bio-effectors) AND (detection OR monitoring OR tracking OR traceability). We excluded keywords that severely restricted the number of relevant publications due to redundant results or inappropriate occurrences (too high or too low). Words and their combinations were used to retrieve a significant amount of bibliographic records (about 700 in our case). Then, the obtained records were checked for their redundancy in order to exclude any overlap of terms. The Scopus search highlighted similar terms used to refer to microbial-based products, biofertilizers, bioinoculants, and consortia. This has created some confusion in the microbial-inoculant literature, making the search to identify the relevant publication more complex. Moreover, the search was restricted to publications (article, review, book chapter, book, and short survey) written in English and excluded papers from the subject areas "medicine", "pharmacology" and "energy". The Scopus search was conducted on 8 May 2020, and for this reason, 2020 publications were incomplete, and the results could 
be underestimated. The EndNote file containing the database of the bibliographic records is reported as Supplementary Material (Table S1).

\subsection{Bibliometric Mapping and Clustering}

A general quantitative description of the bibliographic records was conducted. A word cloud chart representing the co-authors' affiliations of the publications on soil microbial inoculants application and detection were constructed using different font sizes related to the number of publications from different countries. The number of publications was counted, considering all the co-authors of a paper.

Based on the retrieved publications, bibliometric maps were created using the software VOSviewer version 1.6.5.0 (Centre for Science and Technology Studies, Leiden University, The Netherlands (https://www.vosviewer.com/)). The software was specifically developed for creating, visualizing, and exploring science's bibliometric maps [49]. Using VOSviewer, term maps were produced. A term map, also called a co-word map, is a two-dimensional representation of a research field, in which strongly related terms are located close to each other, and the weaker the relationship is between terms, the bigger the distance is between them. Thus, term maps provide overviews for identifying the structure of a topic. The terms occurring in titles, abstracts, and keywords of publications were extracted and represented in the maps as circles. Only terms occurring at least eight times were extracted from the retrieved publications. The software displays the elements of maps by using the VOS (Visualization of Similarities) mapping technique, which is closely related to the multidimensional scaling method [49,50].

The VOS mapping technique allows us to minimize a weighted sum of squared Euclidean distances between all pairs of items through an optimization process. This mapping approach allows aligning terms on the map in a way that the distance between each pair of terms represents their similarity as accurately as possible. Before starting with the analysis in VOSviewer, a thesaurus file (text file) was created to ensure consistency for different terms' spelling and synonyms (an example: Actinobacteria and actinobacterium). VOSviewer also offers the possibility to clean the data by omitting the terms considered not relevant for analyses. Using this software functionality, cleaning was carried out by omitting terms related to time, publishers' names, or terms that could be used ambiguously (an example: Today or result). It should be noticed, however, that a term map represents a simplified version of reality, and this can lead to loss of information and a partial representation of the investigated field [51]. This limitation should be considered when interpreting results.

For the scope of the paper were prepared five maps: (1) A term map inherent the time frame 2000-2020; (2) a term map on the period 2000-2014; (3) a term map on the period 2015-2020; (4) a term citation; (5) a term year map.

\subsection{The Term Map}

In a term map, similarities among terms are calculated based on their number of cooccurrences in the title or abstract of the same publication (for further explanation on the method see $[43,44,46,49])$. The larger the number of publications in which two terms co-occur, the stronger the terms are related to each other. Therefore, terms that often co-occur in the same publications are located close to each other in a term map, and less strongly related terms (low co-occurrence) are located further away from each other. Each term is represented by a circle, where its diameter and the size of its label indicate the number of publications where the term appears in the title, abstract, or keywords. Once terms are in the map, the next step is to identify clusters of related terms. Mapping and clustering procedures often rely on different design principles and conventions. However, as shown by [52], the VOS mapping technique and a weighted and parameterized variant of modularity-based clustering can both be derived from the same underlying principle. This justified our choice of a unified approach for mapping and clustering bibliometric networks. It helps to identify sub-fields or specific sub-topics [48]. 
VOSviewer takes a distance-based approach to visualize bibliometric networks and, by default, applies the association strength normalization. After a normalized network has been constructed, the next step is to position the nodes in the network in a two-dimensional space in such a way that strongly related nodes are located close to each other while weakly related nodes are located far away from each other [53]. For this purpose, VOSviewer uses a clustering technique that can be seen as a kind of weighted variant-of-modularity-based clustering [52]. The technique requires an algorithm to solve an optimization problem. For this purpose, VOSviewer uses the smart local moving algorithm introduced by Waltman and Van Eck [54]. The software uses a weighted and parameterized variant of modularitybased clustering called VOS clustering technique [52,54]. The assignment of terms to the same cluster depends on their co-occurrences in the title or abstract of publications. More specifically, terms that often co-occur are strongly related to each other and are assigned automatically to the same cluster [55]. Terms with a low co-occurrence or no-occurrences at all are assigned to different clusters. A cluster that is made up of terms of the same colors represents a research theme in which one or more research topics can be identified. Although VOSviewer offers the option of changing the number of clusters by changing the resolution parameters, was used the default setting of one. The same approach has been applied to the bibliographic information on the same publication dataset in order to observe the countries of the co-authorship map to observe the collaborative clustering of the countries based on soil microbial inoculants application and detection publications.

\subsection{The Term Year Map}

In the case of the term year map, the color of a term indicates the average publication year of all the publications in which the term occurs. As for the previous term citation map, colors that range from blue (mean year term presence 2010 or earlier), to green (2013) to red (2016 or later) were used. Therefore, blue terms are those occurring mainly in older publications, while red terms occur mainly in more recent publications. Only a subset of all labels used to avoid overlapping labels is displayed in the maps. The mean values of the average publication year for each group obtained by the cluster analysis was tested on the null hypothesis of the same median (Kruskal-Wallis test), the distributions not being normal (Shapiro-Wilk test), and homoscedasticity (Levene test); Mann-Whitney pairwise comparisons Bonferroni corrected post hoc test was applied. Basic statistics were performed using the software Past version 2.17 (Paleontological Museum, Oslo, Norway) [56].

\subsection{The Term Citation Map}

In addition, it also produced the term citation map. A term citation map analyzes the scientific impact of specific topics, whereas a term year map performs a timeline analysis of the research topics. More specifically, in the term citation map, the color of a term is determined by the average citation impact of the publications where the term occurs, thus reflecting the average citation impact for the term rather than by cluster (as in the term map). The number of citations of each publication to avoid biases related to the age of a publication (older publications are expected to be more cited) is divided by the average number of citations of all publications appearing in the same year. This produces a publication's normalized citation score ranging from 0.5 to 2 . In the map, the colors are assigned according to the score, ranging from blue (average score of 0.5 ) to green (average score of 1.25) to red (average score of 2). Therefore, a blue (cold) or red (hot) term indicates that publications in which the term occurs have low or high average citation impacts, respectively [57]. The mean values of the average publication year for each group obtained by the cluster analysis was tested on the null hypothesis of the same median (KruskalWallis test), the distributions not being normal (Shapiro-Wilk test), and homoscedasticity (Levene test); Mann-Whitney pairwise comparisons Bonferroni corrected post hoc test was applied. Basic statistics were performed using the software Past [56] 


\subsection{Limitations}

There are some limitations in the term map analysis regarding both the production and the exploration of results. The interpretation of a bibliometric map is not always straightforward. There are mainly two kinds of limitations with the use of such a technique: Those generated by the data, and those imposed by the map. During the creation of the bibliometric dataset, the record's availability could be limited, and potentially contain a certain amount of noise (mainly due to the arbitrary keywords' choice for the primary search). The synonyms and homonyms represent another kind of problem that could arise (although this is usually solved with an accurate thesaurus realization). The visualization through maps is generally used for orientations using a simplified representation of reality. Such a representation implies a loss of information. VOSviewer generates an inevitable loss of information due to the two-dimensional representation of the terms in a Euclidean space. Despite these limitations, depending on researcher errors and bibliometric mapping constrains, term map analysis represents a useful tool to support experts to improve their knowledge on a particular domain [48].

\section{Results}

\subsection{Publication Trends: Countries, Subject Category, Journals}

A total of 682 scientific publications were retrieved from Scopus database (Available online: https:/ /www.scopus.com/ (accessed on 8 May 2020), encompassing over 20 years. Approximately $88 \%$ of them are research papers, while the remaining $12 \%$ is distributed as follows: $8.2 \%$ reviews, $3 \%$ book chapters, and $0.8 \%$ short surveys. There were 152 different journals' published papers regarding the topic. The top ten journals, in terms of number of papers, are: Applied and Environmental Microbiology $(n=33 ; 5.3 \%)$, Applied Microbiology and Biotechnology $(n=30 ; 4.8 \%)$, Science of Total Environment $(n=29 ; 4,7 \%)$, Environmental Science and Pollution Research $(n=27 ; 4.3 \%)$, Chemosphere $(n=25 ; 4.05 \%)$, Journal of Hazardous Materials $(n=25 ; 4.05 \%)$, FEMS Microbiology Ecology $(n=23 ; 3.7 \%)$, International Biodeterioration and Biodegradation $(n=16 ; 2.6 \%)$, Plant and Soil $(n=16$; $2.6 \%)$, and Biodegradation $(n=15 ; 2.43 \%)$ (Table 1$)$. Figure 1 shows the number of papers regarding soil microbial inoculants application and detection, published from 2000 to 2020. Two periods were analyzed: 2000-2014 and 2015-2020, in order to have a homogeneous number of papers in the two groups.

Table 1. The most productive journals in soil microbial inoculants application research.

\begin{tabular}{cccc}
\hline Rank. & Journal & $\boldsymbol{n}^{\circ}$ Publications & \% Frequencies \\
\hline 1 & Applied and Environmental Microbiology & 33 & 5.3 \\
2 & Applied Microbiology and Biotechnology & 30 & 4.9 \\
3 & Science of the Total Environment & 29 & 4.7 \\
4 & Environmental Science and Pollution Research & 27 & 4.4 \\
5 & Chemosphere & 25 & 4.1 \\
6 & Journal of Hazardous Materials & 25 & 4.1 \\
7 & FEMS Microbiology Ecology & 23 & 3.7 \\
8 & International Biodeterioration and Biodegradation & 16 & 2.6 \\
9 & Plant and Soil & 16 & 2.6 \\
10 & Biodegradation & 15 & 2.4 \\
11 & Journal of Environmental Management & 15 & 2.4 \\
12 & Soil Biology and Biochemistry & 15 & 2.4 \\
13 & Journal of Applied Microbiology & 13 & 2.1 \\
14 & Microbiological Research & 13 & 2.1 \\
16 & Environmental Science and Technology & 12 & 1.9 \\
17 & Microbial Ecology & 12 & 1.9 \\
& Plos One & 12 & 1.9 \\
\end{tabular}




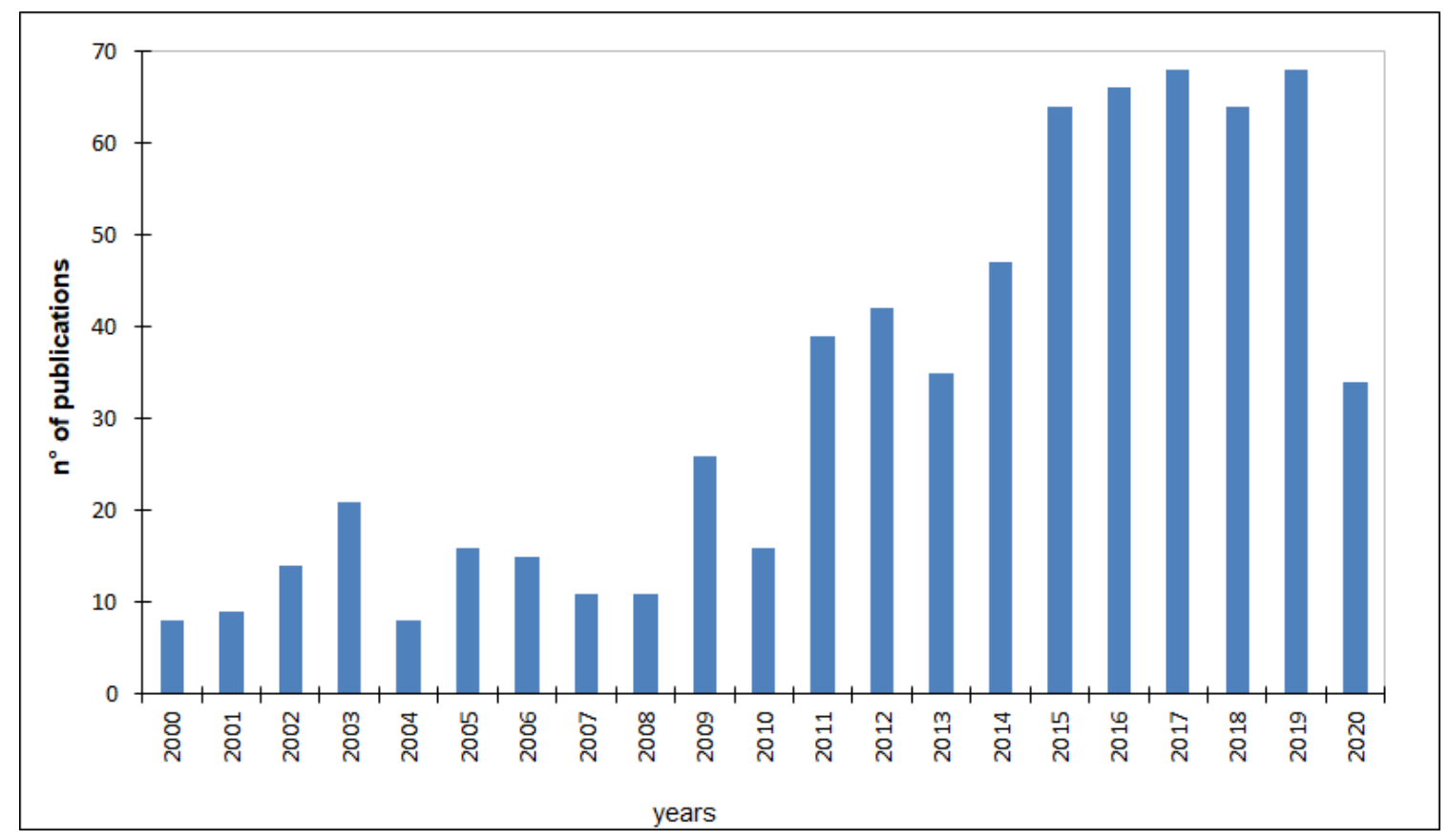

Figure 1. Trend of soil microbial inoculants application publications from 2000 to 2020 . The histogram represents the number of the papers per year.

During 2000-2014, the total number of publications was lower (46.6\%) compared to the ones published during the 2015-2020 period (53.4\%). The number of publications slowly increased from 2009, paving the way for a significant increase after 2014.

Table 1 reports the number of publications for the most active journals. It does not surprise the trend of disciplines involved in the publications; Table 2 lists the 10 main Scopus subject categories including at least 15 papers and up to a maximum number of 362 from 2000 to 2020.

Table 2. The top ten subject categories publishing at least 15 papers.

\begin{tabular}{ccc}
\hline Subject Category & $\boldsymbol{n}^{\circ}$ of Publications & \% Frequencies \\
\hline Environmental Science & 362 & 28.5 \\
Immunology and Microbiology & 267 & 21.0 \\
Agricultural and Biological Sciences & 266 & 20.9 \\
Biochemistry, Genetics and Molecular Biology & 190 & 14.9 \\
Chemistry & 54 & 4.2 \\
Chemical Engineering & 44 & 3.5 \\
Earth and Planetary Sciences & 23 & 1.8 \\
Materials Science & 18 & 1.4 \\
Multidisciplinary & 17 & 1.3 \\
Engineering & 15 & 1.2 \\
Others & 15 & 1.2
\end{tabular}

Authors representing a total of 71 countries published at least 1 paper focused on soil microbial inoculant application and related issues such as soil microbial community, bioremediation, biodegradation, and soil microbial inoculant detection. Figure 2 shows the word cloud chart-representing the countries with the highest number of publications: China $(12.8 \%, n=120)$, India $(10.8 \%, n=101)$, United States $(9.95 \%, n=93)$, Germany $(4.9 \%$, $n=46)$, Spain $(4.3 \%, n=40)$, France, as well as Italy with the same statistics $(3.9 \%, n=37)$, and Australia $(3.8 \%, n=36)$. In total, Europe accounts for $39.4 \%$ of publications. 


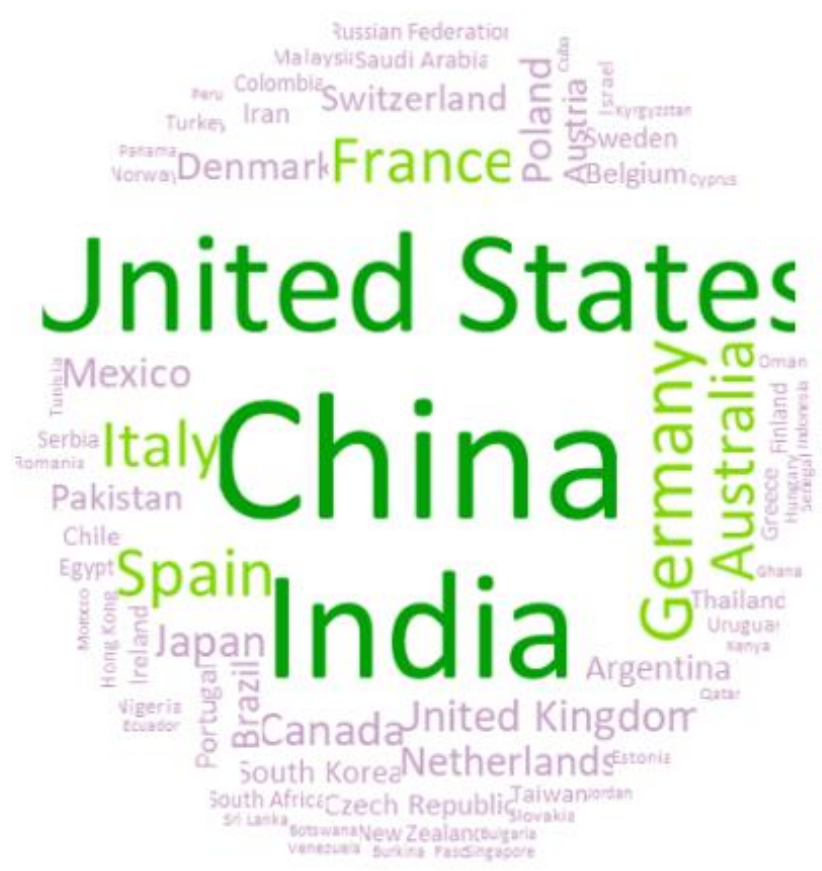

Figure 2. The word cloud chart of the countries. The size of the letters is based on the number of publications per country.

Figure 3 displays the collaboration among countries, represented in three clusters: Asia, USA, and Europe; however, there was a patchy distribution of the collaborations (same color): E.U. (red cluster) with some exceptions (Germany, Portugal, Denmark), together with Pakistan, Iran, and Canada; USA (green cluster) with Australia, India, Mexico, Brazil, and other countries; China (blue cluster) with Denmark, Sweden, UK, and Portugal. Linkages represent the grade of co-authorship among countries. There are also many linkages among clusters as proof of strict collaboration.

f

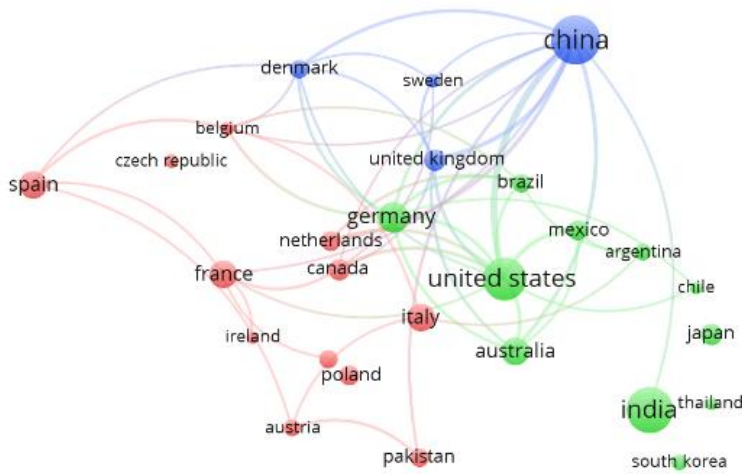

Figure 3. Collaborative clustering map of the countries based on the affiliations of co-authorships in Scopus soil microbial inoculants publications. The three different colors represent different collaboration clusters. The size of the country is based on the number of publications. The connecting lines indicate the 50 strongest co-occurrence links between countries. 


\subsection{An Overview of the Research Term World Evolution}

Figure 4 shows the 134 terms map covering the period from 2000 to 2014. The terms displayed on the map are grouped into three clusters. The red cluster (right side of the map) is mainly represented by the terms related to the use of microorganisms in agriculture and related issues, such as "application", "inoculant" or "bioinoculant", "treatment", "biocontrol agent", but also "field trial", "rhizobacteria", "efficacy", "solubilization", and "trait". The blue cluster (upper side) grouped terms are related to microbial "species", but also microbes and "community structure", showing terms dealing with technical/methodological issues like "PCR", "16sRNA gene", and "relative abundance". The green cluster (left side of the map) grouped terms such as "consortia", "isolate", and "concentration", as well as terms associated with the development of the microbial inoculants, that start from microbial "isolation" and the search for desirable "traits". This cluster also grouped terms related to soil microbial inoculants application ("biostimulation", "degradation" or "biodegradation", "bioremediation", and "PAH degradation") showing the widest used inoculants ("Plant growth-promoting rhizobacteria [PGPR]", "Pseudomonas", "Enterobacter").

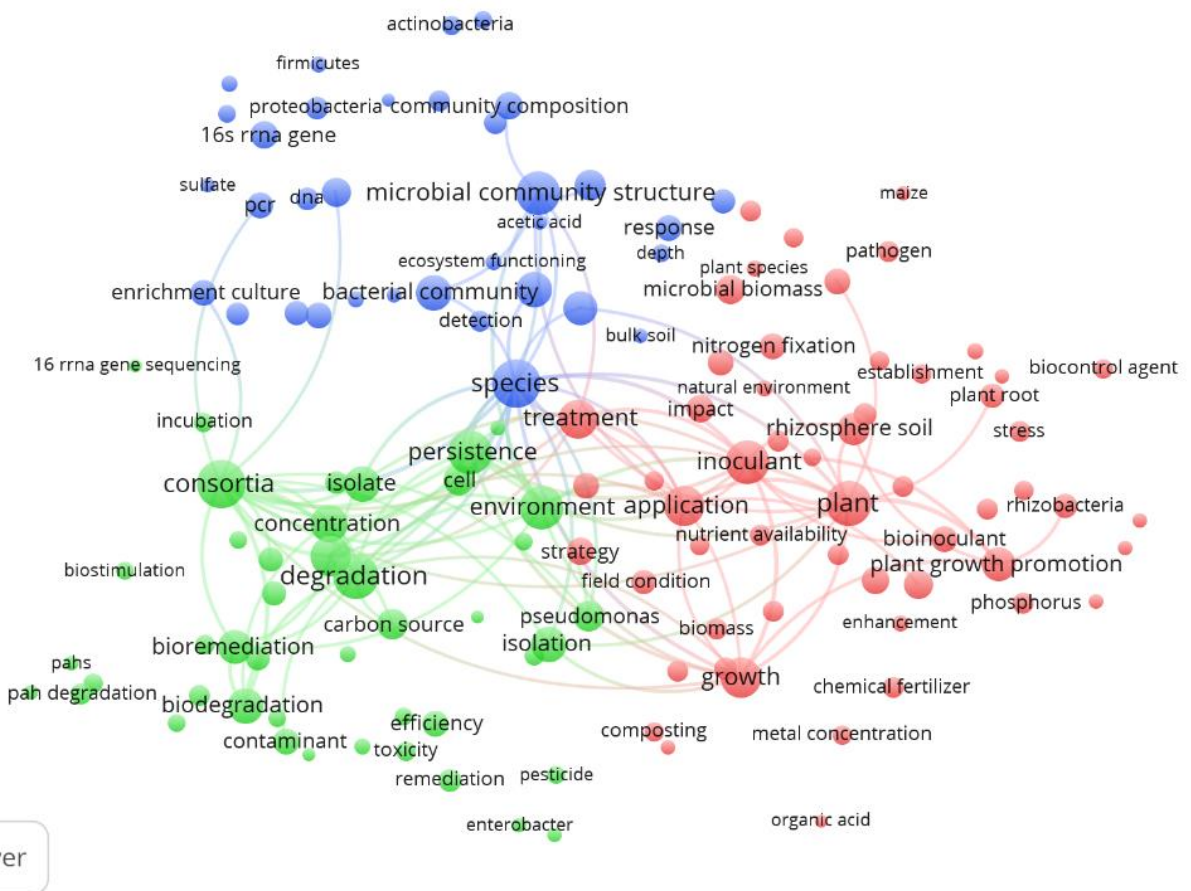

Figure 4. The terms clustering map based on the Scopus soil microbial inoculants publications from 2000 to 2014 . The red, green, and blue colors represent the terms belonging to different clusters. The size of the terms is based on the number of occurrences. The connecting lines indicate the 100 strongest co-occurrence links between terms.

Similarly, Figure 5 represents a terms' map based on only the last 5 years (2015-2020), thus, describing the recent research trend and the evolution of the research topic. During this period, the number and the kind of terms shown on the map highlight the strong research interest in "growth", "plant", "application", "plant growth promotion", and "inoculant" (shown in the red cluster). Three clusters also contain terms such as "isolation", "microbiome", "soil quality", "accumulation", "sustainable agriculture", "soil fertility", "crop productivity", "management", "agricultural soil", "fertilizer", "fungal strain", and "crop productivity". The blue cluster shows the same terms observed in the previous map (Figure 4, 2000-2014), but also contains some new terms such as "plant species", "bulk soil", "soil property", and "soil sample". Interestingly, the map contains the term "interaction", which has a co-occurrence with "species", "soil microbial community", and "microbiome", highlighting the emerging issue concerning the interaction between the inoculant and the native soil microbiome. The green cluster further stresses the same research topics of the 
previous map (Figure 4, 2000-2014), but underlining the terms appeared during the last years (2015-2020) with a higher occurrence, like "treatment", "composting", "degradation", "gene", "strategy", and "persistence". Interestingly, the term "persistence" is closely linked to "degradation".

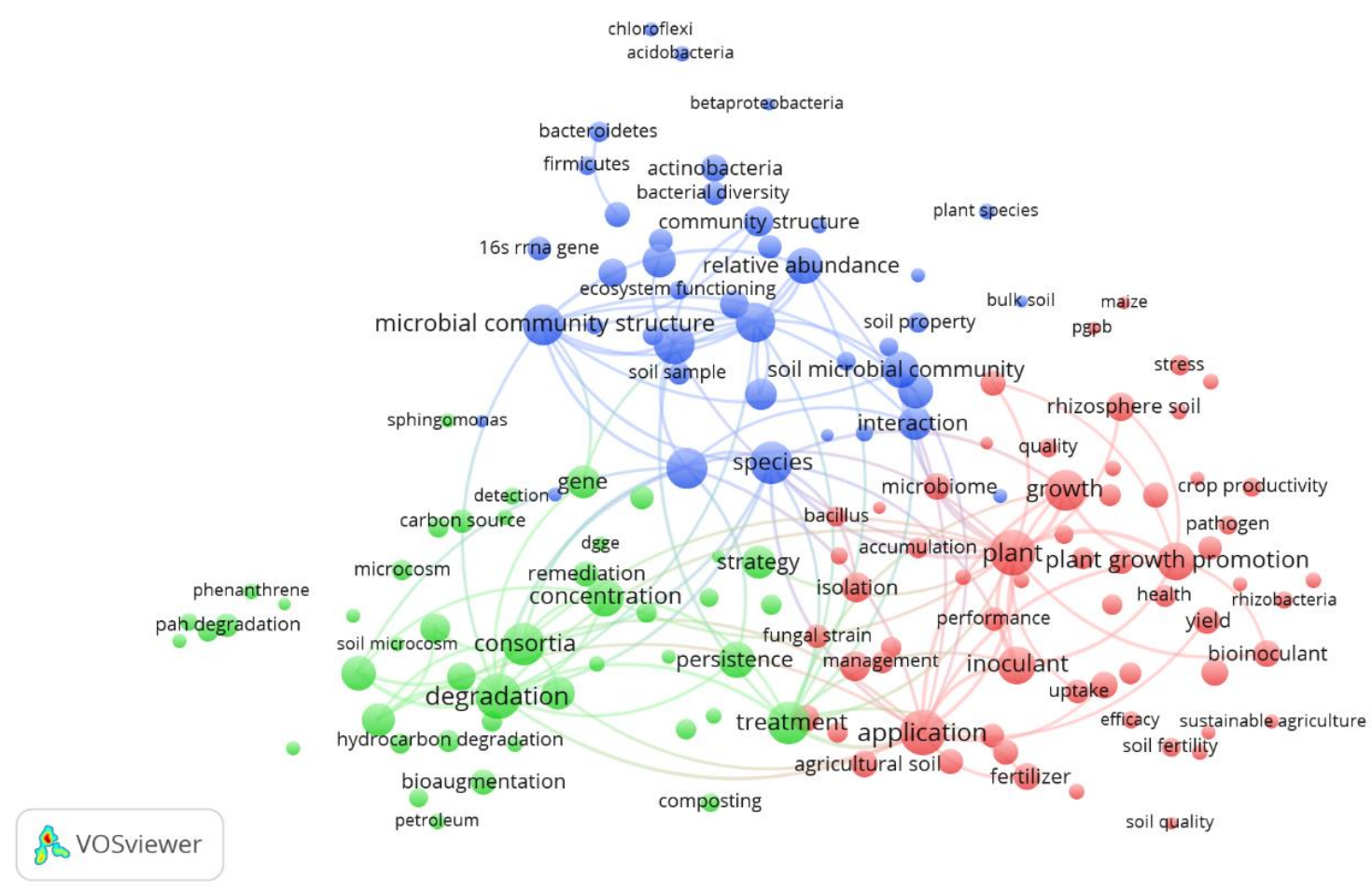

Figure 5. The terms clustering map based on the Scopus soil microbial inoculants publications from 2015 to 2020. Different colors (red, green, blue) represent the terms belonging to different clusters. The size of the term is based on the number of occurrences. The connecting lines indicate the 100 strongest co-occurrence links between terms.

Figure 6 shows the complete world term map for the period 2000 to 2020. It reveals that terms used in early publications are mainly those represented by clusters based on a publication from 2000 to 2014. In this term map, remarkably, the number of terms first detected in the period 2000-2014 present an increasing occurrence, and likewise, they are grouped into three clusters. The red cluster contained terms such as "application", "growth", "plant", "bioinoculant", "treatment", and "inoculant", as well as merging terms such as "biofertilizer", "sustainability", and "association". There are terms like "rhizobacteria", "microbial biomass", "application", "inoculant", "growth", that displayed a higher occurrence, indicating the increasing importance of research topics; this suggests that soil microbial inoculant application increased starting by the end of 2014. This red cluster also contains new terms such as "uptake", "trait", "IAA", "manure", "soil quality", "Azotobacter", "field trial", and "pesticide", suggesting the growing interest and focus on topics concerning soil microbial inoculants and related issues. In the time frame 2000-2014, there were terms (like "strategy") that, in the global world terms map referring to the period 2000-2020, appeared in a different cluster, and this is mirrored by different co-occurrence links between the terms. Nevertheless, the terms of this red cluster represent more traditional research of soil microbial inoculant application. The blue cluster (upper side) groups the terms already observed in the previous map (period 2000-2014; Figure 4), but here the terms showed higher occurrences. This refers to terms like "microbial community structure", "bacterial community", "16SrRNA gene", "Actinobacteria", and "PCR". In this map, there also appeared new terms such as "Verrucomicrobia", "Firmicutes", "Bacteroidetes", "Acidobacteria", and "gene". Moreover, this map contains the term "biodiversity" and "stability". The green cluster shows terms covering the application of soil microbial inoculants 
such as "species", "consortia", "incubation", "efficiency", "isolation", "PAH degradation", "hydrocarbon degradation", "remediation", and "accumulation". Most of these terms have been observed in the previous maps (Figures 4 and 5), but in the current map they are displayed with a higher occurrence in agreement with the increasing research trend of the latest years. The map also shows a higher occurrence of the term "detection" that identifies a new trend in the methodology. In line with this consideration, terms as "microcosm", "anaerobic condition", and "GC-MS" are referred to different methodological trends.

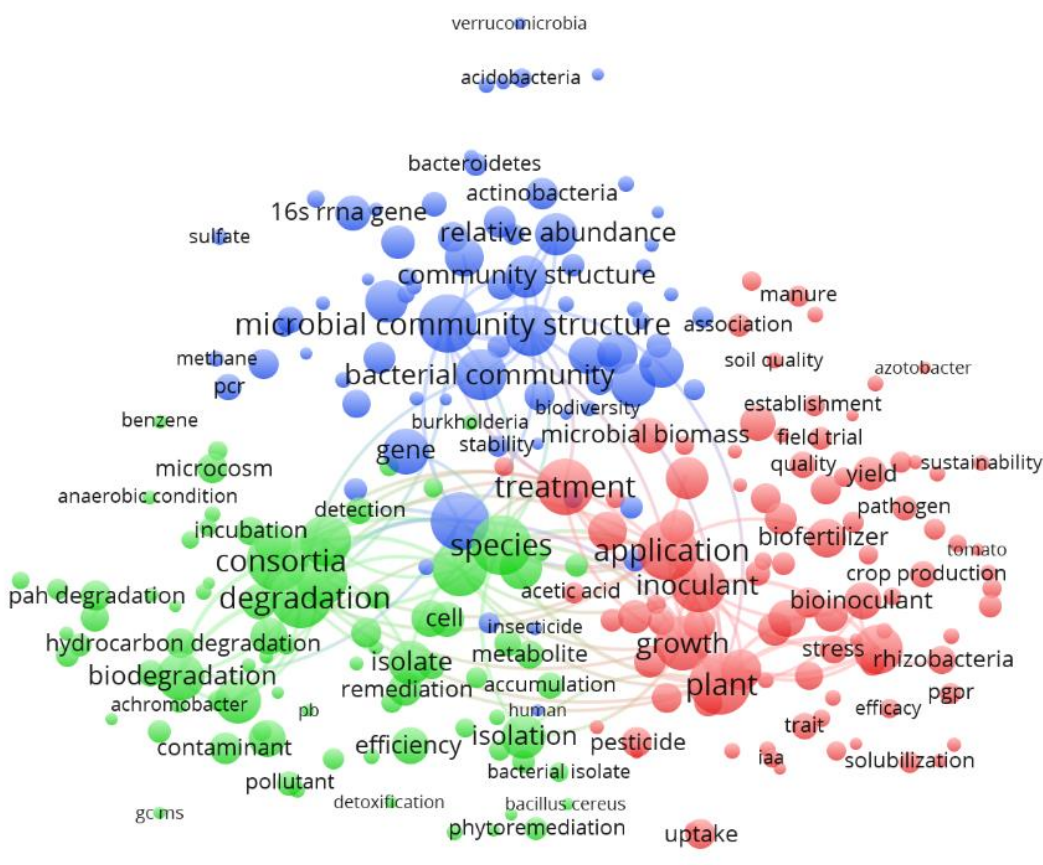

VOSviewer

pseudomonas aeruginosa

Figure 6. The terms clustering map based on the Scopus soil microbial inoculants publications from 2000 to 2020 . Different colors (red, green, blue) represent the terms belonging to different clusters. The size of the term is based on the number of occurrences. The connecting lines indicate the 100 strongest co-occurrence links between terms.

\subsection{Research Topic Per Year and Their Citation Impact}

Figure 7 shows the world term map per year. By observing the colors of the map, it can be seen that the terms used in the early publications are patchily distributed in the three clusters of Figures 4-6. These are terms related to "microbial community", to bacterial/fungal isolates introduced to the soil to enhance a target function, to "establishment" or successful persistence of a microbial strain after being inoculated into a novel environment. Nevertheless, these are terms related to "microcosm" experiments. In recent publications, the relevant terms were much more related to sustainability, to the sustainable management of "plant growth", or to the application of inoculants for a different purpose. One of the main target applications concerns the "PAH degradation". When looking at the last years, the map reveals "biofertilizer", "sustainability", "Verrucomicrobia", "Acidobacteria", "Actinobacteria", "Bacteroidetes", "pesticide", and "uptake". Considering the mean values of the average publication's year for the three groups obtained by the cluster analysis (Figure 6), the red cluster showed a more recent value (2014.2), followed by the green one (2013.4) and the blue one (2013.6). These were tested on the null hypothesis of the same median, the distributions not being normal (Shapiro-Wilk test; $p<0.05$ ), and homoscedasticity (Levene test; $p>0.05$ ); Kruskal-Wallis test rejected the null hypothesis of equality of median. Mann-Whitney pairwise comparisons Bonferroni corrected post hoc test showed a significant difference $(p<0.001)$ between red and green clusters. 


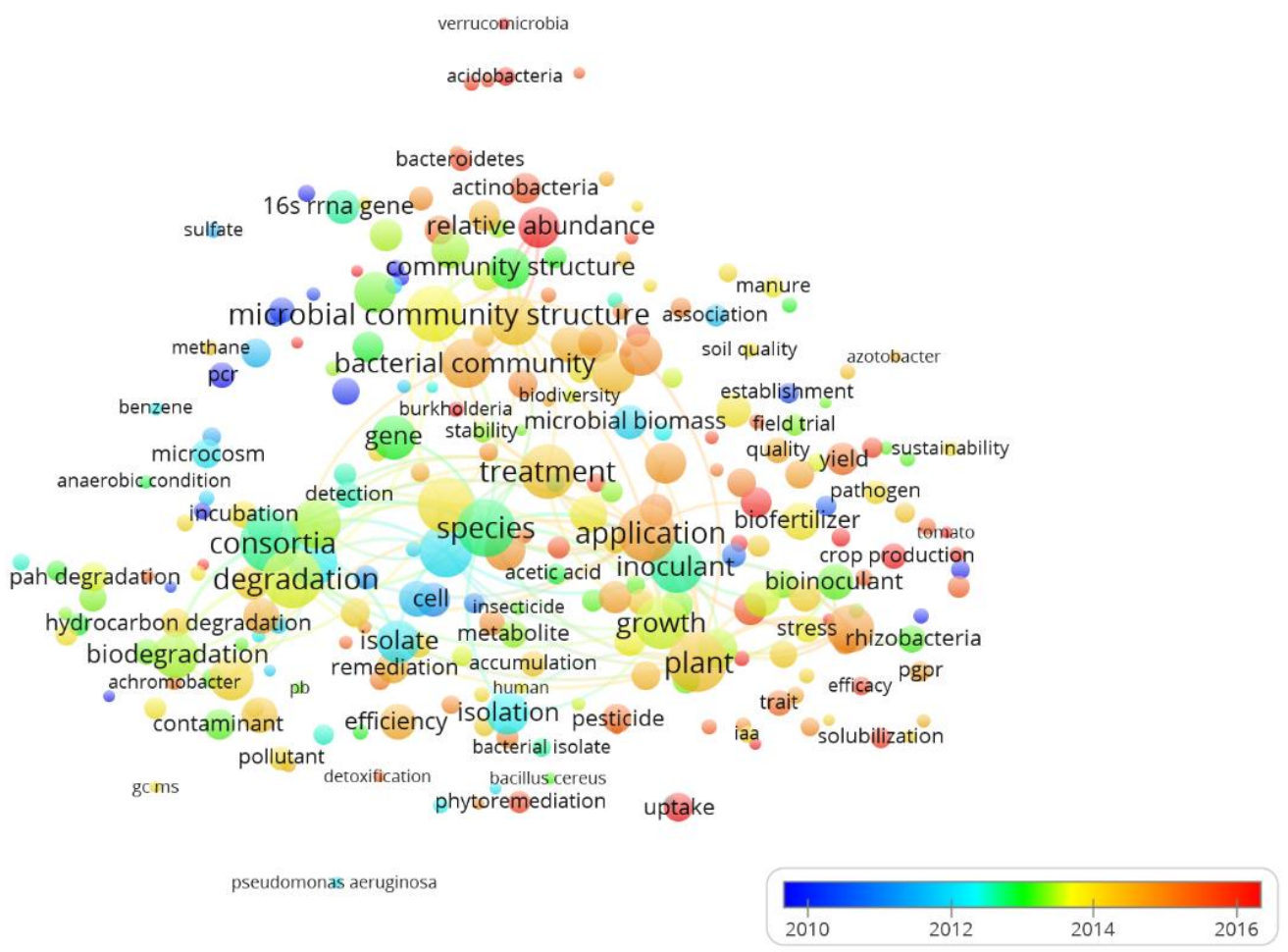

Figure 7. Term map indexed per publication year based on all the Scopus plant phenotyping publications. The time scale is represented by different colors. The size of the term is based on the number of occurrences. The connecting lines indicate the 100 strongest co-occurrence links between terms.

Figure 8 shows the term map of normalized citation rate based on all the Scopus soil microbial inoculants application publications/citations. The colors here are used to identify the average citation impact of publications in the term's occurrences. The "hot" (or red) terms indicate the highest average citation impacting ones. Hot terms are mainly located in the upper and right side of the map (blue and red cluster). Terms citations reveal that publications highly used the following terms: "plant pathogen", "soil quality", "Stenotrophomonas", "Streptomyces", "organic pollutant", "soil microbial biomass", "PGPB", "rhizoremediation", "Rhodococcus", "soil fertility", "arbuscular mycorrhizal fungi", "indigenous microbial community", "interaction", "association", "soil $\mathrm{pH}^{\prime}$, "pathogen", "xenobiotic", "NPK", "Sphingomonas" and "Burkholderia". What was observed underlines the important role of microbial inoculants in agricultural productivity as well as in "remediation", but also that agents of the disease have been cited more frequently than those reporting "consortia", "detection", "microbial community structure", and "efficiency". Considering the mean values of the normalized citation rate for the three groups obtained by the cluster analysis (Figure 6), the red cluster showed the highest citation rate (1.13), followed by the green one (1.02) and the blue one (0.98). These were tested on the null hypothesis of the same median being the distributions not normal (Shapiro-Wilk test; $p<0.05$ ) and homoscedasticity (Levene test $p>0.05$ ); Kruskal-Wallis test rejected the null hypothesis of equality of median. Mann-Whitney pairwise comparisons Bonferroni corrected post hoc test showed a significant difference $(p<0.05)$ between red and green clusters. 


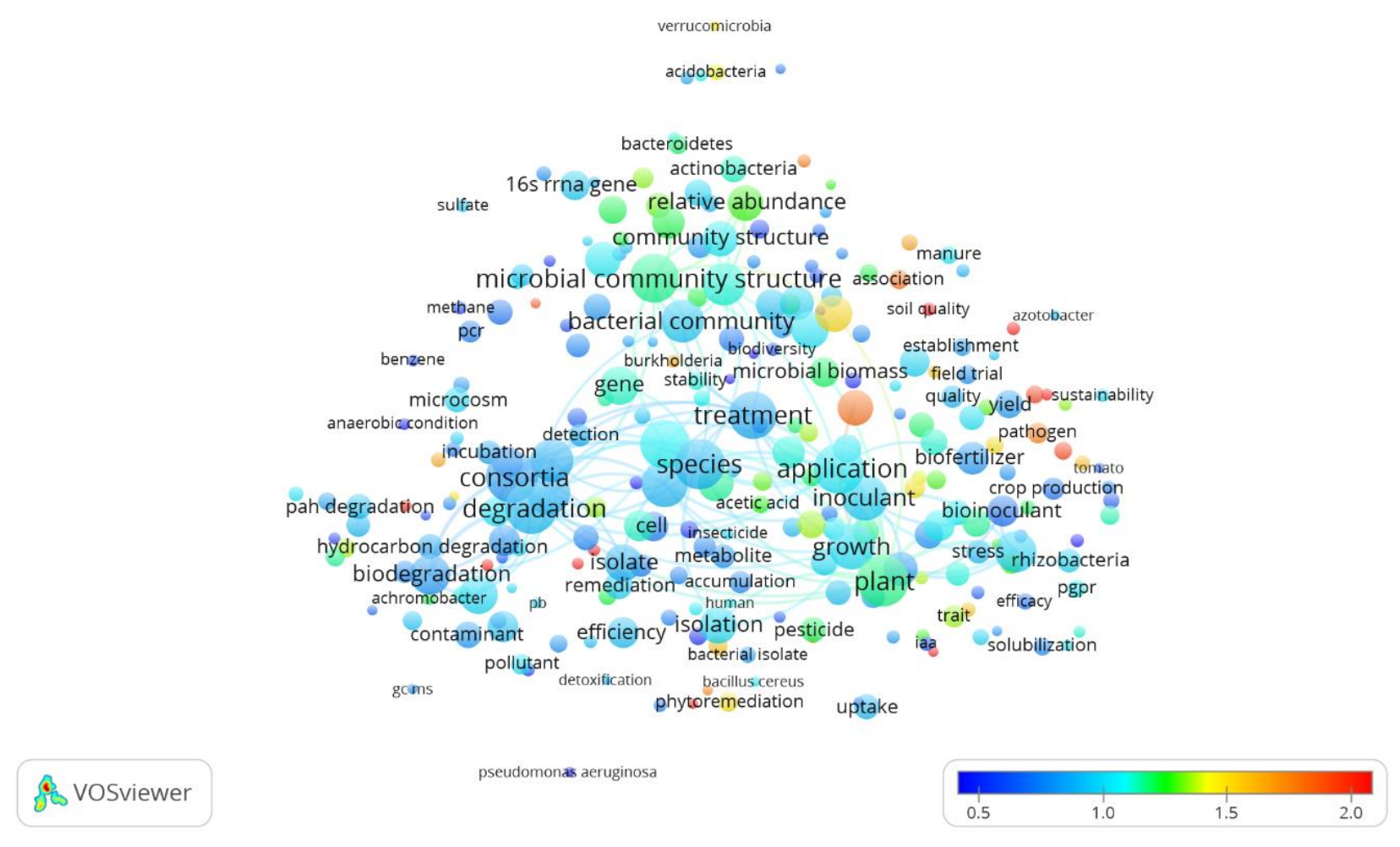

Figure 8. Term map based indexed per citation rate based on all the Scopus plant phenotyping publications/citations. The normalized citation rate scale is represented by the different colors. The size of the term is based on the number of occurrences. The connecting lines indicate the 100 strongest co-occurrence links between terms.

\section{Discussion}

In the last decades, soil microbes have shown great potential for plant nutrition and protection applications in agriculture, and a wide variety of microbial-based products have been applied so far $[6,12,14-28,38]$. However, the efficacy of soil microbial inoculants under field conditions still remains unpredictable and unreliable, as many factors affect the effectiveness of these products, making them inefficient in cases such as nutrient-poor or unbalanced soils, salinity, increasing temperatures, water stress, diseases, and pests, among others [6,7]. To overcome these factors, several studies have been addressed to gain better knowledge on the intrinsic properties of soil microbial inoculants, seeking the main relevant traits promoting plant health and nutrition.

To our knowledge, the current science mapping analysis is the first tentative to chart state of the art, evaluating the research trend on soil microbial inoculants and unravelling the strengths and weaknesses of their application. In this paper, with "microbial inoculants", we refer to all the microbial-based products used for plant nutrition and protection, and any distinction among biostimulants, biofertilizers, biopesticides, or other bioproducts is beyond the scope of this work.

\subsection{Publication Trends: Countries, Subject Category, Journals}

Starting from the analysis of 682 publications published from 2000 to 2020, the present work obtained a set of maps displaying term history and co-occurrences through which emerged the temporal evolution of the research topics and the emerging ones. According to this survey, it was observed that during the first temporal frame (2000-2014), the total number of publications was low when compared to the 2015-2020 period. However, it is remarkable that the 2000-2008 period accounts for only $16.6 \%$ of the total papers, whereas the number of publications slowly increased since 2009, reaching the maximum value in 2019. The low number of publications during the first nine years may mark a turning point of the scientific interest on the broad field of microbial inoculants, while the years 
2000-2008 can be considered as the beginning "blooming era" of microbial inoculants in agriculture. Nowadays, the application of microbial inoculants is quickly spreading in a context where humanity is facing high food demand, loss of cultivable land, and climate change with severe environmental impacts $[3,29,36,38]$. The urgent need for research investment in the microbial-based products for agriculture is mirrored by significant and exponentially increasing publication numbers. Despite the ancient traces of the existence of microbial inoculants, this finding highlights the renewed interest of the scientific community in microbial inoculant research and development, considering the environment status and the increasing food demand. It is a common belief that conventional agricultural management is not sustainable anymore [58-62]. Indeed, the excessive or improper application of chemical fertilizers and pesticides caused severe and adverse effects on the environment, and now there are efforts to strengthen and reduce their harmful impacts on the environment [63]. In this scenario, it is striking to observe how "environmental science, immunology, and microbiology" represent about the $50 \%$ of published papers, thus reflecting the actual research trend trajectory and agreeing with the main focus of journals that showed the highest number of publications: Applied and Environmental Microbiology, Applied Microbiology and Biotechnology, and FEMS Microbiology Ecology. All these journals focus mainly on microbiology and applied microbiology subjects, while Science of Total Environment is a multidisciplinary journal. Environmental Science and Pollution Research, Chemosphere, and Journal of Hazardous Materials report a broad environmental research field with emphasis on chemical compounds and bioremediation. In fact, although the agricultural sector is the main purpose of microbial inoculants, these can also be used for soil bioremediation, as well as for plant protection $[64,65]$. These findings suggest the multidisciplinary character of the research carried out on soil microbial inoculants.

Furthermore, the research interest is shared by 71 countries contributing with at least one paper to the bibliometric data set. The leading countries in microbial inoculants research are China, India, USA, and Germany, followed by Spain, France, and Italy. China leads the number of patents related to microbial inoculants accounting for more than 800 patents, followed by India with more than 100 [29]; thus, it is not surprising that these countries lead the research in microbial inoculants worldwide, accounting for $12.8 \%$ and $10.8 \%$, respectively, of all the related publications. Interestingly, it was recently reported that Argentina and India are in the top ten countries for the application of inoculants or 'biofertilizers' [29]. In contrast, the present study estimates that Argentina accounts for $1.6 \%$ of publications. However, in the USA, around $15 \%$ of the area cropped with soybean is inoculated with microbial inoculants [29]. This is not surprising looking at the Scopus database research results, where United States accounted for $9.95 \%$ of the total publications. However, in the present survey, it emerges that European countries contribute to the microbial inoculant research representing alone $39.4 \%$ of the publication number. This clearly highlights the European situation, where this kind of product is consistently produced and commercialized. Bashan and co-workers estimated that the market value of plant growth-promoting rhizobacteria/bacteria (PGPR/PGPB), biological control agents, and biostimulants was valued at USD 6.00 Billion in 2016, and that this will grow following an annual rate of $13.8 \%$ up to more than 14.5 Billion by 2023 , whereas it is predicted that demand for chemical-based products such as pesticides is expected to decline due to emerging regulatory issues and consumer demand for food with low chemical residues [38] For example, the EU has set a goal to replace $50 \%$ of chemical pesticide usage with biological solutions by 2030 [66]. Moreover, a recent review underlined the emerging EU demand for bio-based products, including microbial-based products, estimated to grow up to $€ 50$ Billion by 2030 [67]. The review surveyed the state of the art, the challenges, and the needs for EU action, also looking, for example, at the EU's demand for bio-based products. Microbial-based products fall into this subject, which aims to implement a systematic approach to food and agriculture, reducing the chemical and pesticides inputs for healthy soil, for sustainable management of the environmental resources. 


\subsection{Research Term World Evolution and Their Citation Impacts}

The evolution of the terms describing the "microbial inoculants" related research topics during the 2000-2020 period is displayed on world term maps (Figures 4-6), where such terms are grouped in three different clusters. The first cluster (red color,) includes terms related or describing the "application" of bioinoculants. Terms frequently used in early publications (2000-2014) are "inoculant", "bioinoculant", "rhizobacteria", "biological agent", "application", "field conditions", and the "efficacy" due to agricultural beneficial "traits". Together with further recurrent terms like "plant', "treatments", "pathogen", "biocontrol agent", "growth", and "plant growth promotion", suggest that microorganisms were typically used in biocontrol or to promote plant growth. This observation also agrees with the occurrence of terms like "sustainable agriculture" in more recent publications (2015-2020), thus underlining a research interest toward sustainable management of agricultural soil and the application of microbial inoculants. In the production and application scenario, terms like "establishment" suggest new approaches for promoting inoculant persistence, and thus the successful survival and growth of a microbial inoculant after its introduction into the soil. Interestingly, in more recent papers, the term "soil" appeared more frequently than before (i.e., "soil quality", "soil fertility', "agricultural soil", "rhizosphere soil"). Indeed, it is not surprising that "soil quality or fertility" is one of the main targets in the application of microbial inoculants, since the way to move toward more sustainable agriculture is to increase soil fertility, nutritional quality, and yield while reducing the input of chemical fertilizers and/or pesticides $[2,68]$. It is no coincidence that "sustainable agriculture" is located very close to "soil fertility and quality" terms in the map, describing the recent research trends and the increasing attention paid to sustainability. Furthermore, the appearance of "fungal strain" associated with the former terms, also suggests the increased use of fungal inoculants, even if less than bacteria [69]. When considering the term map of the entire period (2000-2020), terms like "application", "treatment", "inoculant", "growth", and "plant" showed higher occurrence, confirming their relevance during the overall period. Moreover, terms like "biofertilizers", "stability", and "field trials" were observed here while were hidden or poorly represented in the previous maps, thus indicating that more research should be focused on testing such products in the field to achieve reliable and significant results under real conditions.

Most of the terms of the blue cluster converge toward technical and methodological issues. More specifically, an emphasis on technology-driven aspects that take advantage of PCR-based tools in exploiting bacterial genetic resources and community structure emerges. However, in the early publications (2000-2014), poor attention has been paid in monitoring soil microbiomes and exploring the interactions occurring between inoculants and native soil microbial communities, even though it is well known that soil native microbiomes may affect the inoculant "establishment" [70]. On the other hand, most recent papers (2015-2020) showed novel terms like "interaction" that have a co-occurrence with "species", "soil microbial community", and "microbiome", thus highlighting the strong interaction between the inoculant and the native soil microbiome. It is also important to note the higher occurrence of terms such as "bacterial diversity". In fact, compared to the early publications, it indicates the increasing attention paid to "microbial diversity" and "ecosystem functioning", with particular emphasis on belowground diversity [71]. As already observed in the red cluster, the term "soil" appeared much more frequently than in the early period (i.e., "soil sample", "soil microbial community", "soil property", "bulk soil"), confirming its emerging role for the development of reliable and successful soil microbial inoculants. In this scenario, it fits the increasing effort for the development of a biodiversity-based soil management strategy that meets the need to better understand a complex ecosystem belowground, where plants, soil, and microorganisms are considered as a unique "meta-organism". In the last years, as microbial inoculants knowledge matures and inoculants rapidly evolve, interacting with a plethora of microbes naturally present in the host environment, it is particularly important to focus on the "interactome" concept [72], as well as on plant-soil-microbe interactions. For example, the combined use 
of the recent "omics" technologies and high-throughput phenotyping could facilitate a better understanding of the physiological and molecular mechanisms driving the plantsoil-microbe interactions and the application procedure of microbial inoculants in different cropping systems.

In the green cluster, the terms that resulted mainly related to the successful development and application of microbial strains as inoculants, evidencing the most used ones (PGPR, Pseudomonas, Enterobacter, Bacillus, etc.) for purposes other than agriculture. In this sense, it was recently reported that the beginning of the PGPR research field has witnessed the use of specific species/strains, later paving the way to the mixture of different bacterial species and raising new and more technical issues [38]. The occurrence of terms like "consortia", "isolate", and "concentration" in the early publications of the green cluster raises the question related to the use of "consortia" over the last decade rather single inoculum, but also describes the "isolation" of microbial inoculant strains raising the question of the "identification" discussed in depth by Bashan and co-workers [38,73]. Moreover, it is evident that bacteria represent the most used microbes for inoculant production. Then, there is the occurrence of the term "concentration", that may refer to the dose of specific microorganisms in the soil that may impact on the establishment and functioning of inoculative species in the host soil, or to the concentration of contaminants and toxic compounds to be (bio)-removed. Lastly, terms like "persistence" were observed, thus highlighting the emerging need of detecting the persistence and the fate of microbial inoculants in the soil since their application $[11,31,35,74]$. When looking at the green cluster, "degradation", "remediation," and "persistence" terms exhibited an increasing occurrence over time, thus suggesting to what extent the use of microbial inoculants is gaining successful results for environmental purposes and what is the emerging research trend that goes beyond the production and application of microbial inoculants. Such terms also indicate the increasing research moving forward a better understanding of the mechanism of interaction of the microbial inoculants with the native soil microbiomes, the fate and persistence of inoculants once added into the soil, and of the variety of potential microbes to be used. Therefore, understanding of plant-soil-microbe interactions, together with the persistence of microbial inoculants in soil, represents an important challenge for this research topic and for facilitating the diffusion of these bio-products across the relevant agricultural sectors, including organic farming [75]. For example, Trabelsi and co-workers demonstrated that inoculation of PGPM affects several native soil microbes in different ways [76]. However, very little is known on the effects of inoculant introduction on the native soil microbial communities and the potential establishment of unexpected invasive species with unknown consequences for local communities and their functions [11].

The microbial inoculants storytelling emerges, also analyzing the citation impacts over time. In fact, more basic research topics tend to fall within the early publications, while terms related to the recent advances were highly cited in the last period (2015-2020), pointing out highly cited topics from both the red cluster (i.e., "crop production", "biofertilizer", "efficacy", "sustainability", "yield", "pesticide", "uptake") and blue cluster (i.e., "relative abundance", "Verrucomicrobia", "Acidobacteria", "Actinobacteria"). Moreover, it is worth noting that term citations describe the "hot" topics, and terms that have been most frequently used fall into the red (i.e., "microbial biomass", "soil quality", "sustainability", "pathogen") and green clusters (i.e., "PAH degradation", "isolate", "remediation"), in agreement with what was retrieved in the year citation map.

Overall, these results lead to better understand what is still needed to promote the development and the application of microbial inoculants in agriculture. For example, the impressive development of molecular and "omics" techniques occurred in the last few years promoted both the selection and the characterization of many microbes with agriculturally valuable functions. However, such approaches should be better integrated and applied under a "field perspective", thus providing useful knowledge for the development of both single-strain inoculants and synergistic consortia able to achieve reliable and significant results under real conditions. Nevertheless, our data indicated an increasing 
attention paid to understand the interrelationship among microbial inoculants and native soil microbiota, and this also appears by looking at terms like "community structure" or "microbial biomass".

\subsection{Missing or Poorly Represented Research Topics}

In addition to the relevant terms retrieved in the database, it is also important to look at the "missing" or poorly represented terms. For example, our output reported a low occurrence of publications describing failures of the experiments or negative results. In fact, terms as "limits", "failure", "disadvantage", etc., were not detected among the relevant bibliographic records, thus overrepresenting the potential benefits of the microbial inoculant applications compared to their limitations. However, this result is not surprising and is in accordance with Bashan et al. [38]. In their paper, the authors recall the necessity that scientific publications should also unravel the failure of the experiments, because while extensive literature reports successful case studies of microbial inoculants application, failures, or disadvantages are poorly published. This gap of knowledge might be one of the reasons that have limited the overall comprehension of the real potential of microbial inoculants so far, thus determining considerable barriers to the widespread use of such products [33-36]. However, the poor reliability and difficulties assessing in-field success of microbial inoculants may be due to several reasons. For example, although the importance of soil ecology in inoculant survival has been established, most of research on soil microbial inoculants continued to be focused on target functional traits observed in vitro or controlled conditions, rather than establishment/survival traits and interactions with soil and its native microbiome. In addition, our results suggest that such an integrated view has not been sufficiently considered until recently. Moreover, terms related to the inoculant production process (i.e., "fermentation", "formulation", "processes", "additives", etc.) are also missing, representing another potential limitation to their wide application $[38,77]$. Nevertheless, the overall economic competitiveness of microbial inoculants based on the overall up-stream and down-stream operational costs should be also considered [77].

Notably, terms related to "regulation" and "legislation" issues did not clearly emerge, thus revealing a gap on the overall research trend which might explain the limited scientific support to the regulatory implementation of this category of products. This may indicate a poor interest of this scientific community in such aspects, but it may also be due to the inconsistencies occurred in the definition of several microbial-based products, generally defined with terms such as biofertilizers, bioinoculants, biostimulants, bioproducts, or other terms frequently considered, rather inappropriately, as synonyms, as previously reported by Malusà and Vassilev [7]. This hypothesis is also consistent with the high number of redundant or similar terms used to refer to microbial-based products we found during the analysis of the relevant terms retrieved from the bibliographic records of our work (see also Section 2.1). This has created some confusion in both the scientific literature and in the market of microbial-based products for plant nutrition and protection, thus making much more complicated the definition of their regulatory framework. Actually, the different regulatory processes and legal provisions defined for microbial biopesticides and biostimulants or biofertilizers do not correspond to what happens in nature, where many microorganisms can exhibit multifunctional properties or different properties under different conditions.

\section{Conclusions}

This study highlighted the temporal evolution of the research topics related to the use of microbial inoculants in agriculture along the last two decades and will be useful toward projecting the future research on microbial inoculants and their application. In fact, their importance in agriculture is dramatically increasing and agricultural microbial-based products are among the fastest-growing industries globally. Our findings revealed the multidisciplinary character of the research carried out on soil microbial inoculants during the last two decades, with emphasis on the agricultural sector, but also environmental 
research, chemical compounds, and bioremediation. EU countries provided almost the $40 \%$ of the overall publications, indicating European countries as research leaders in microbial inoculants worldwide.

Overall, the terms retrieved by our research indicate that the scientific literature on soil microbial inoculants may be conceptualized into three main thematic areas:

Use and application of microbial inoculants: Most of the research topics are focused on microbial products developed for plant growth promotion and bioremediation purposes. Whereas the most recent literature focused the attention on soil and environmental sustainability, the high occurrence of terms like "persistence" indicated the emerging need for detecting and monitoring the persistence and the fate, respectively, of the microbial inoculants applied to the soil.

Technical/methodological issues: PCR-based and "omics" tools were frequently used for the selection and the characterization of many microbes with agriculturally valuable functions. However, such approaches should be better integrated under a "field perspective", thus providing useful knowledge for the development of microbial inoculants able to achieve reliable and significant results under real conditions. Interestingly, among the latest studies (2015-2020), an increasing attention was paid to address interactions occurring between inoculants and native soil microbial communities.

Development of microbial inoculants: The earlier studies (2000-2014) were mainly focused on single bacterial species/strain, whereas during the last decade, the research field moved toward the use of microbial consortia, including fungi, which can provide functional benefits over single-strain inoculants, but the development of synergistic consortia might be complicated.

Nevertheless, our results also revealed the lack of relevant terms such as "failure", "disadvantage", "inconsistency", etc., thus indicating that such aspects have not been sufficiently taken into account by scientists, and this is likely one of the reasons why the success of most of the current microbial inoculants in the field remains unpredictable and unreliable. Scientists should be encouraged to publish their successful experiments as well as their failures. Of course, the uncertainness on the beneficial effects of microbial inoculants is also related to the methodological approach used to select the microbial strains and to the formulation process adopted for the production of the microbial inoculants. Moreover, the low occurrence of terms related to "regulation" and "legislation" issues revealed a gap on the overall research trend which might likely explain the limited scientific support to the regulatory implementation of this category of products. Thus, further effort should be made in order to improve the use and efficacy of microbial inoculants, considering their application as a common task for agriculture. For this purpose, it is essential to ultimately understand how such inoculants interact with soil and its native microbiota, as well as the key processes regulating the plant-soil-microbe interactions across different cropping systems and soil types. It has been proposed to exploit the "soil holobiont" through an approach similar to the one used in the Human Microbiome Project. In fact, considering the similar colonization and establishment strategies adopted by the human gut and rhizosphere microbiomes, promising strategies for the exploitation of soil microbial inoculants appeared based on prebiotic, probiotic, symbiotic, and postbiotic products [77]. An example of such effort is represented by the EXCALIBUR project, entitled "Exploiting the multifunctional potential of belowground biodiversity in the horticultural farming" (www.excaliburproject.eu) funded by the H2020 Programme of the European Commission (grant n. 817946), which plans to test new multifunctional microbial inoculants (bio-inocula) and bio-effectors on three model crops (tomato, apple, strawberry) under different experimental and open-field conditions across Europe, thus aiming to deepen the knowledge on interactions between plant, soil, micro-, meso-, and macro-organisms, and the links and dynamics between native soil biodiversity and agricultural practices. The project aims to provide all the information on fermentation, formulation consortia, and plant-soil-microbe interactions that other authors in their recent issues [38,75] have encouraged to be given. 
Overall, this knowledge will be used to create a predictive model and innovative tools to help farmers optimize application methods of the microbial inoculants in a certain environment, according to the native soil biodiversity and features. Thus, integrating such a microbiome-driven soil management strategy in precision farming will be a promising approach for the future.

Supplementary Materials: The following are available online at https:/ / www.mdpi.com/2077-047 2/11/2/158/s1, Table S1: EndNote file.

Author Contributions: Conceptualization, S.M. and C.C.; methodology, C.C. and F.P.; formal analysis, L.C., C.C. and F.P.; writing-original draft preparation, L.C., C.C., F.P., S.M.; writing-review and editing, L.C. and S.M. All authors have read and agreed to the published version of the manuscript.

Funding: This work was conducted in the frame of the EXCALIBUR project, funded by the European Union's Horizon 2020 research and innovation program (grant agreement No. 817946).

Institutional Review Board Statement: Not applicable.

Informed Consent Statement: Not applicable.

Data Availability Statement: The data presented in this study are available in Supplementary Material (Table S1).

Acknowledgments: We are grateful to Luz De Bashan for constructive and valuable comments, which were of great help in preparing the manuscript.

Conflicts of Interest: The authors declare no conflict of interest. The funders had no role in the design of the study; in the collection, analyses, or interpretation of data; in the writing of the manuscript, or in the decision to publish the results.

\section{References}

1. Adesemoye, A.O.; Torbert, H.A.; Kloepper, J.W. Enhanced plant nutrient use efficiency with PGPR and AMF in an integrated nutrient management system. Can. J. Microbiol. 2008, 54, 876-886. [CrossRef]

2. Adesemoye, A.O.; Torbert, H.A.; Kloepper, J.W. Plant growth-promoting rhizobacteria allow reduced application rates of chemical fertilizers. Microb. Ecol. 2009, 58, 921-929. [CrossRef]

3. Malusà, E.; Pinzari, F.; Canfora, L. Efficacy of biofertilizers: Challenges to improve crop production. In Microbial Inoculants in Sustainable Agricultural Productivity; Springer: New Delhi, India, 2016; pp. 17-40. [CrossRef]

4. Mazid, S.; Rajkhowa, R.C.; Kalita, J.C. A review on the use of biopesticides in insect pest management. Int. J. Sci. Adv. Technol. 2011, 1, 169-178.

5. Richardson, A.E.; Barea, J.M.; McNeill, A.M.; Prigent-Combaret, C. Acquisition of phosphorus and nitrogen in the rhizosphere and plant growth promotion by microorganisms. Plant. Soil 2009, 321, 305-339. [CrossRef]

6. Bashan, Y.; de-Bashan, L.E.; Prabhu, S.R.; Hernandez, J.P. Advances in plant growth-promoting bacterial inoculant technology: Formulations and practical perspectives (1998-2013). Plant. Soil 2014, 378, 1-3. [CrossRef]

7. Malusà, E.; Vassilev, N. A contribution to set a legal framework for biofertilizers. Appl. Microbiol. Biotechnol. 2014, 98, 6599-6607. [CrossRef]

8. Kilian, M.; Steiner, U.; Krebs, B.; Junge, H.; Schmiedeknecht, G.; Hain, R. FZB24 Bacillus subtilis-mode of action of a microbial agent enhancing plant vitality. Pflanzenschutz Anzenschutz Nachr. Bayer 2000, 1, 72-93.

9. Nobbe, F.; Hiltner, L. Inoculation of the soil for cultivating leguminous plants. US Pat. 1896, 570, 813.

10. Bashan, Y. Inoculants of plant growth-promoting bacteria for use in agriculture. Biotechnol. Adv. 1998, 16, 729-770. [CrossRef]

11. Trabelsi, D.; Mhamdi, R. Microbial inoculants and their impact on soil microbial communities: A review. Biomed. Res. Int. 2013, 863240. [CrossRef]

12. Lucy, M.; Reed, E.; Glick, B.R. Application of free-living plant growth-promoting rhizobacteria. Antonie Van Leeuwenhoek 2004, 86, 1-25. [CrossRef]

13. Vessey, J.K. Plant growth promoting rhizobacteria as biofertilizers. Plant Soil 2003, 255, 571-586. [CrossRef]

14. Hayat, R.; Ali, S.; Amara, U.; Khalid, R.; Ahmed, I. Soil beneficial bacteria and their role in plant growth promotion: A review. Ann. Microbiol. 2010, 60, 579-598. [CrossRef]

15. Yanni, Y.G.; Rizk, R.Y.; Abd El-Fattah, F.K.; Squartini, A.; Corich, V.; Giacomini, A.; de Bruijn, F.; Rademaker, J.; Maya-Flores, J.; Ostrom, P.; et al. The beneficial plant growth promoting association of Rhizobium leguminosarum bv. trifolii with rice roots. Funct. Plant Biol. 2001, 28, 845-870. [CrossRef]

16. Bardi, L.; Malusà, E. drought and nutritional stresses in plant: Alleviating role of rhizospheric microorganisms. In Abiotic Stress: New Research; Haryana, N., Punj, S., Eds.; Nova Science Publishers Inc.: Hauppauge, NY, USA, 2012; pp. 1-57. 
17. Okon, Y.; Labandera-Gonzalez, C.A. Agronomic applications of Azospirillum: An evaluation of 20 years worldwide field inoculation. Soil. Biol. Biochem. 1994, 26, 1591-1601. [CrossRef]

18. Subramanian, K.; Charest, C. Acquisition of $\mathrm{N}$ by external hyphae of an arbuscular mycorrhizal fungus and its impact on physiological responses in maize under drought-stressed and well-watered conditions. Mycorrhiza 1999, 9, 69-75. [CrossRef]

19. Bennett, P.C.; Choi, W.J.; Rogers, J.R. Microbial destruction of feldspars. Miner. Manag. 1998, 8, 149-150. [CrossRef]

20. Bennett, P.C.; Rogers, J.R.; Choi, W.J. Silicates, silicate weathering, and microbial ecology. Geomicrobiol. J. 2001, 18, 3-19. [CrossRef]

21. Liu, D.; Lian, B.; Dong, H. Isolation of Paenibacillus sp. and assessment of its potential for enhancing mineral weathering. Geomicrobiol. J. 2012, 29, 413-421. [CrossRef]

22. Supanjani, H.H.S.; Jung, S.J.; Lee, K.D. Rock phosphate potassium and rock solubilizing bacteria as alternative sustainable fertilizers. Agron Sustain. Dev. 2006, 26, 233-240. [CrossRef]

23. Fukami, J.; Ollero, F.J.; Megías, M.; Hungria, M. Phytohormones and induction of plant-stress tolerance and defense genes by seed and foliar inoculation with Azospirillum brasilense cells and metabolites promote maize growth. AMB Express $2017,7,153$. [CrossRef]

24. Fukami, J.; Cerezin, P.; Hungria, M. Azospirillum: Benefits that go far beyond biological nitrogen fixation. AMB Express 2018, 8 , 1-12. [CrossRef]

25. Fukami, J.; De La Osa, C.; Ollero, F.J.; Megías, M.; Hungria, M. Co-inoculation of maize with Azospirillum brasilense and Rhizobium tropici as a strategy to mitigate salinity stress. Funct. Plant. Biol. 2018, 45, 328-339. [CrossRef] [PubMed]

26. Berg, G.; Köberl, M.; Rybakova, D.; Müller, H.; Grosch, R.; Smalla, K. Plant microbial diversity is suggested as the key to future biocontrol and health trends. FEMS Microbiol. Ecol. 2017, 93, 1-9. [CrossRef]

27. Singh, N.; Raina, S.; Singh, D.; Ghosh, M.; Heflish, A.I. Exploitation of promising native strains of Bacillus subtilis with antagonistic properties against fungal pathogens and their PGPR characteristics. J. Plant. Pathol. 2017, 99, 27-35. [CrossRef]

28. Xiang, N.; Lawrence, K.S.; Kloepper, J.W.; Donald, P.A.; Mcinroy, J.A. Biological control of Heterodera glycines by spore-forming plant growth-promoting rhizobacteria (PGPR) on soybean. PLoS ONE 2017, 12, 181-201. [CrossRef]

29. Sanches Santos, M.; Nogueira, M.A.; Hungria, M. Microbial inoculants: Reviewing the past, discussing the present and previewing an outstanding for the use of beneficial bacteria in agriculture. AMB Express 2019, 9, 205. [CrossRef]

30. Canfora, L.; Malusà, E.; Tkaczuk, C.; Tartanus, M.; Łabanowska, B.; Pinzari, F. Development of a method for detection and quantification of B. brongniartii and B. bassiana in soil. Sci. Rep. 2016, 6, 22933. [CrossRef] [PubMed]

31. Canfora, L.; Abu-Samra, N.; Tartanus, M.; Łabanowska, B.H.; Benedetti, A.; Pinzari, F.; Malusà, E. Co-inoculum of Beauveria brongniartii and B. bassiana shows in vitro different metabolic behaviour in comparison to single inoculums. Sci. Rep. 2017, 7, 1-15. [CrossRef] [PubMed]

32. Alori, E.; Dare, M.O.; Babalola, O.O. Microbial inoculants for soil quality and plant health. In Sustainable Agriculture Reviews; Springer: Cham, Switzerland, 2017; pp. 281-307. [CrossRef]

33. Mitter, B.; Brader, G.; Pfaffenbichler, N.; Sessitsch, A. Next generation microbiome applications for crop production-limitations and the need of knowledge-based solutions. Curr. Opin. Microbiol. 2019, 49, 59-65. [CrossRef] [PubMed]

34. Malusá, E.; Canfora, L.; Pinzari, F.; Tartanus, M.; Łabanowska, B.H. Improvement of Soilborne Pests Control with Agronomical Practices Exploiting the Interaction of Entomophagous Fungi. In Plant-Microbe Interactions in Agro-Ecological Perspectives; Singh, D., Singh, H., Prabha, R., Eds.; Springer: Singapore, 2017. [CrossRef]

35. Rilling, J.J.; Acuña, J.A.; Nannipieri, P.; Cassan, F.; Maruyama, F.; Jorquera, M.A. Current opinion and perspectives on the methods for tracking and monitoring plant growth-promoting bacteria. Soil Biol. Biochem. 2018, 130, 205-219. [CrossRef]

36. Kaminsky, L.M.; Trexler, R.V.; Malik, R.J.; Hockett, K.L.; Bell, T.H. The inherent conflicts in developing soil microbial inoculants. Trends Biotechnol. 2019, 37, 140-151. [CrossRef] [PubMed]

37. Hart, M.M.; Antunes, P.M.; Chaudhary, V.B.; Abbott, L.K. Fungal inoculants in the field: Is the reward greater than the risk? Funct. Ecol. 2018, 32, 126-135. [CrossRef]

38. Bashan, Y.; Prabhu, S.R.; de-Bashan, L.E.; Kloepper, J.W. disclosure of exact protocols of fermentation; identity of microorganisms within consortia; formation of advances consortia with microbe-based products. Biol Fertil Soils 2020, 56, 443-445. [CrossRef]

39. Liu, B.; Eydallin, G.; Maharjan, R.P.; Feng, L.; Wang, L.; Ferenci, T. Natural Escherichia coli isolates rapidly acquire genetic changes upon laboratory domestication. Microbiology 2017, 163, 22-30. [CrossRef]

40. Li, T.; Ho, Y.S.; Li, C.Y. Bibliometric analysis on global Parkinson's disease research trends during 1991-2006. Neurosci. Lett. 2008, 441, 248-252. [CrossRef] [PubMed]

41. Tarkowski, S.M. Environmental health research in Europe-Bibliometric analysis. Eur J. Public Health 2007, 17, 14-18. [CrossRef]

42. Falagas, M.E.; Karavasiou, A.I.; Bliziotis, I.A. A bibliometric analysis of global trends of research productivity in tropical medicine. Acta Trop. 2006, 99, 155-159. [CrossRef]

43. Nardi, P.; Di Matteo, G.; Palahi, M.; Scarascia Mugnozza, G. Structure and evolution of mediterranean forest research: A science mapping approach. PLoS ONE 2016, 11, e0155016. [CrossRef] [PubMed]

44. Costa, C.; Schurr, U.; Loreto, F.; Menesatti, P.; Carpentier, S. Plant phenotyping research trends; a science mapping approach. Front. Plant Sci. 2019, 9, 1933. [CrossRef]

45. Costa, C.; Fanelli, E.; Marini, S.; Danovaro, R.; Aguzzi, J. Global deep-sea biodiversity research trends highlighted by science mapping approach. Front. Mar. Sci. 2020, 7, 384. [CrossRef] 
46. Pallottino, F.; Biocca, M.; Nardi, P.; Figorilli, S.; Menesatti, P.; Costa, C. Science mapping approach to analyze the research evolution on precision agriculture: World, E.U. and Italian situation. Precis Agric. 2018, 19, 1011-1026. [CrossRef]

47. Hamilton, C.A.; Vacca, R.; Stacciarini, J.M.R. The emergence of team science: Understanding the state of adoption research through social network analysis. Adopt. Foster. 2017, 41, 369-390. [CrossRef]

48. Ioannoni, V.; Vitale, T.; Costa, C.; Elliot, I. depicting communities of Romani studies: On the who; when and where of Roma related scientific publications. Scientometrics 2020, 122, 1473-1490. [CrossRef]

49. van Eck, N.J.; Waltman, L. Software survey: VOSviewer; a computer program for bibliometric mapping. Scientometrics 2010, 84, 523-538. [CrossRef]

50. Van Eck, N.J.; Waltman, L. Text mining and visualization using VOSviewer. arXiv 2011, arXiv:1109.2058.

51. Van Raan, A.F. Advances in bibliometric analysis: Research performance assessment and science mapping. In Bibliometrics. Use and Abuse in the Review of Research Performance; Wenner-Gren International Series; Blockmans, W., Engwall, L., Weaire, D., Eds.; Portland Press: London, UK, 2014; pp. 17-28.

52. Waltman, L.; Van Eck, N.J.; Noyons, E.C. A unified approach to mapping and clustering of bibliometric networks. J. Informetr 2010, 4, 629-635. [CrossRef]

53. Van Eck, N.J.; Waltman, L. Visualizing bibliometric networks. In Measuring Scholarly Impact: Methods and Practice; Ding, Y., Rousseau, R., Wolfram, D., Eds.; Springer: Berlin/Heidelberg, Germany, 2014; pp. 285-320.

54. Waltman, L.; van Eck, N.J. A smart local moving algorithm for large-scale modularity-based community detection. Eur. Phys. J. B 2013, 86, 471. [CrossRef]

55. Cobo, M.; López-Herrera, A.; Herrera-Viedma, E.; Herrera, F. Science mapping software tools: Review, analysis, and cooperative study among tools. J. Am. Soc. Inf. Sci. 2011, 62, 1382-1402. [CrossRef]

56. Hammer, Ø.; Harper, D.A.; Ryan, P.D. PAST: Paleontological statistics software package for education and data analysis. Palaeontol Electron. 2001, 4, 9.

57. Van Eck, N.J.; Waltman, L.; van Raan, A.F.; Klautz, R.J.; Peul, W.C. Citation analysis may severely underestimate the impact of clinical research as compared to basic research. PLoS ONE 2013, 8, e62395. [CrossRef] [PubMed]

58. Godfray, H.C.J.; Beddington, J.R.; Crute, I.R.; Haddad, L.; Lawrence, D.; Muir, J.F.; Pretty, J.; Robinson, S.; Thomas, S.M.; Toulmin, C. Food security: The challenge of feeding 9 billion people. Science 2010, 327, 812-818. [CrossRef]

59. Keeler, B.L.; Gourevitch, J.D.; Polasky, S.; Isbell, F.; Tessum, C.W.; Hill, J.D.; Marshall, J.D. The social costs of nitrogen. Sci. Adv. 2016, 2, e1600219. [CrossRef] [PubMed]

60. Milner, A.M.; Boyd, I.L. Toward pesticidovigilance: Can lessons from pharmaceutical monitoring help to improve pesticide regulation? Science 2017, 357, 1232-1234. [CrossRef] [PubMed]

61. Ray, D.K.; Mueller, N.D.; West, P.C.; Foley, J.A. Yield trends are insufficient to double global crop production by 2050 . PLoS ONE 2013, 8, e66428. [CrossRef]

62. Toyota, K.; Watanabe, T. Recent trends in microbial inoculants in agriculture. Microbes Environ. 2013, 28, 403-404. [CrossRef]

63. Baez-Rogelio, A.; Morales-Garcia, Y.E.; Quintero-Hernandez, V.; Munoz-Rojas, J. Next-generation of microbial inoculants for agriculture and bioremediation. Microb. Biotechnol. 2017, 10, 19-21. [CrossRef]

64. Owen, D.; Williams, A.P.; Griffith, G.W.; Withers, P.J.A. Use of commercial bio-inoculants to increase agricultural production through improved phosphorus acquisition. Appl. Soil Ecol. 2015, 86, 41-54. [CrossRef]

65. Wagner-Döbler, I. Microbial inoculants: Snake oil or panacea? In Bioremediation: A Critical Review; Head, I.M., Singleton, I., Milner, M., Eds.; Horizon Scientific Press: Norfolk, UK, 2003; pp. 259-289.

66. Singh, B.K.; Trivedi, P.; Egidi, E.; Macdonald, C.A.; Delgado-Baquerizo, M. Crop microbiome and sustainable agriculture. Nat. Rev. Microbiol. 2020, 18, 601-602. [CrossRef]

67. Bell, J.; Paula, L.; Dodd, T.; Németh, S.; Nanou, C.; Mega, V.; Campos, P.E.U. ambition to build the world's leading bioeconomyUncertain times demand innovative and sustainable solutions. New Biotechnol. 2018, 40, 25-30. [CrossRef]

68. Fierer, N.; Jackson, R.B. The diversity and biogeography of soil bacterial communities. Proc. Natl. Acad. Sci. USA 2006, 103, 626-631. [CrossRef]

69. Jeffries, P.; Gianinazzi, S.; Perotto, S.; Turnau, K.; Barea, J.M. The contribution of arbuscular mycorrhizal fungi in sustainable maintenance of plant health and soil fertility. Biol. Fertil. Soils 2003, 37, 1-16. [CrossRef]

70. Buck, S.; Rolfe, J.; Lemin, C.; English, B. Establishment of Leucaena in Australia. Trop. Grassl Forrajes Trop. $2019,7,104-111$. [CrossRef]

71. Lawrence, D.; Fiegna, F.; Behrends, V.; Bundy, J.G.; Phillimore, A.B.; Bell, T.; Barraclough, T.G. Species interactions alter evolutionary responses to a novel environment. PLoS Biol. 2012, 10, e1001330. [CrossRef] [PubMed]

72. Van der Putten, W.H.; Klironomos, J.N.; Wardle, D.A. Microbial ecology of biological invasions. ISME J. 2007, 1, 28-37. [CrossRef]

73. Bashan, Y.; Kloepper, J.W.; de-Bashan, L.E.; Nannipieri, P. A need for disclosure of the identity of microorganisms, constituents, and application methods when reporting tests with microbe-based or pesticide-based products. Biol. Fertil. Soils 2016, 52, 283-284. [CrossRef]

74. Silvestri, E.E.; Feldhake, D.; Griffin, D.; Lisle, J.; Nichols, T.L.; Shah, S.R.; Pemberton, A.; Schaefer III, F.W. Optimization of a sample processing protocol for recovery of Bacillus anthracis spores from soil. J. Microbiol. Meth. 2016, 130, 6-13. [CrossRef]

75. Rouphael, Y.; Colla, G. Toward a sustainable agriculture through plant biostimulants: From experimental data to practical applications. Agronomy 2020, 10, 1461. [CrossRef] 
76. Trabelsi, D.; Mengoni, A.; Ben Ammar, H.; Mhamdi, R. Effect of on-field inoculation of Phaseolus vulgaris with rhizobia on soil bacterial communities. FEMS Microbiol. Ecol. 2011, 77, 211-222. [CrossRef] [PubMed]

77. Vassilev, N.; Vassileva, M.; Martos, V.; Del Moral, L.F.G.; Kowalska, J.; Tylkowski, B.; Malusá, E. Formulation of microbial inoculants by encapsulation in natural polysaccharides: Focus on beneficial properties of carrier additives and derivatives. Front. Plant Sci. 2020, 10, 270. [CrossRef] [PubMed] 